\title{
Círculo de Cultura: uma experiência metodológica de conscientização e (trans)formação docente para o acolhimento de crianças com deficiência na creche
}

\section{Circle of Culture: an methodological experience of awareness and teacher's (trans) formation for receptions of disable children in playschool}

\author{
Flávia Alves Bonsanto \\ Mestrado em Educação \\ Universidade Federal de Juiz de Fora (UFJF). \\ Juiz de Fora, MG - Brasil. \\ flavinhabonsanto@gmail.com \\ Sandrelena Da Silva Monteiro \\ Doutorado em Educação \\ Universidade Federal de Juiz de Fora (UFJF). \\ Juiz de Fora, MG - Brasil. \\ sandrelena.monteiro@ufjf.edu.br
}

Resumo: No presente ensaio propomo-nos a analisar as relações dialéticas do sujeito professor e sua formação psíquica com o desenvolvimento de sua atividade de trabalho com adolescentes. A fundamentação teórica utilizada nesse estudo está ancorada em textos de Vygotski (1896-1934), Leontiev (1903-1979), Davidov (1930-1998) e autores contemporâneos que interpretam a realidade a partir do Enfoque Histórico-Cultural. Defendemos, ao longo do estudo, que o desenvolvimento da formação docente, constituído a partir de determinações sociais, é também um aspecto determinante da atividade de trabalho do professor. Trabalho esse que pode criar condições de apropriação de conhecimentos que impulsionem o desenvolvimento psíquico dos estudantes adolescentes, e essa dinâmica, por sua vez, possibilita em ambos o desenvolvimento de uma visão mais ampla e crítica da realidade e de si próprios.

Palavras-chave: Círculo de Cultura. Acolhimento. Conscientização. (Trans)Formação Docente.

Abstract: This article presents the paths built in the interaction between researchers, teachers and children on what the circle of culture constituted a methodological possibility of research. Understood not only as a physical disposition of persons in the occupied space, but as relationships established there, the circle of culture constituted an educative space-time of awareness and teacher's(trans)formation. The research were developed in space-time of a public playschool and has as a goal knowing and (re)mean the conception(s) about welcome of professionals in caring for children whosedevelopment is involved by some disability. The research exercise, grounded in Freire's theory, point to humanized welcome as an original-viable in the horizon, not only in playschool, but in caring of every children and each educational space-time.

Keywords: Circle of Culture. Welcome. Awareness. Teacher (Trans)Formation.

Cite como

\section{(ABNT NBR 6023:2018)}

BONSANTO, Flávia Alves; MONTEIRO, Sandrelena da Silva. Círculo de cultura: uma experiência metodológica de conscientização e (trans)formação docente para o acolhimento de crianças com deficiência na creche. Dialogia, São Paulo, n. 37, p. 1-13, e18913, jan./abr. 2021. Disponível em: https://doi.org/10.5585/dialogia.n37.18913

American Psychological Association (APA)

Bonsanto , F. A., \& Monteiro, S. S. da. (2021, jan./abr.). Círculo de cultura: uma experiência metodológica de conscientização e (trans)formação docente para o acolhimento de crianças com deficiência na creche. Dialogia, São Paulo, 37, p. 1-13, e18913.

https://doi.org/10.5585/dialogia.n37.18913. 
BONSANTO, Flávia Alves; MONTEIRO, Sandrelena da Silva. Círculo de cultura: uma experiência metodológica de conscientização e (trans)formação docente para o acolhimento de crianças com

\title{
Introdução
}

A escrita deste texto é tecida com fios fiados a muitas mãos. O desenho de fundo se fez no encontro entre pesquisadoras, educadoras e crianças em uma creche municipal da cidade de Juiz de Fora, interior de Minas Gerais, em que o acolhimento foi o principal ponto a ser tecido.

Mulheres se reuniram com o propósito de que as crianças fossem as protagonistas. Um encontro para conversar, pensar, fazer e refazer práticas e saberes espaços-temporais. O tema das conversas? $\mathrm{O}$ ato de acolher. Mais especificamente, o acolhimento às crianças com deficiência no espaço-tempo da creche.

Em meio a tantas mulheres, um homem ocupava lugar de convidado ao diálogo: Paulo Freire. E, tendo sua teoria como tear, instrumento necessário à prática dessa tessitura, começamos a reflexão buscando um entendimento para o ato de acolher. $\mathrm{O}$ diálogo com Freire nos propiciou uma aproximação entre o que estávamos entendendo por acolhimento com a ideia de disponibilidade. Segundo ele:

\begin{abstract}
Estar disponível é estar sensível aos chamamentos que nos chegam, aos sinais mais diversos que nos apelam, ao canto do pássaro, à chuva que cai ou que se anuncia na nuvem escura, ao riso manso da inocência, à cara carrancuda da desaprovação, aos braços que se abrem para acolher ou ao corpo que se fecha na recusa. É na minha disponibilidade permanente à vida a que me entrego de corpo inteiro, pensar crítico, emoção, curiosidade, desejo, que vou aprendendo a ser eu mesmo em minha relação com o contrário de mim. E quanto mais me dou à experiência de lidar sem medo, sem preconceito, com as diferenças, tanto melhor me conheço e construo meu perfil. (FREIRE, 1996, p. 151-152).
\end{abstract}

Se disponibilidade e sensibilidade são indispensáveis a uma educação que atenda a toda criança em suas especificidades, estas, sem a devida formação e estudo, correm o risco de causar um retrocesso na prática pedagógica enquanto ato educativo para um mero ato de assistência. Aqui já se compreende que a união dos saberes construídos e conquistados pelas docentes em suas trajetórias formativas, com a disponibilidade aos saberes das crianças, às emoções, às vivências e à construção de novos modos de ser e estar na creche, de maneira dialógica, viabiliza uma atitude inclusiva de abertura à “comunhão” com as diferenças. (MARQUES, 2012).

Nesta dimensão, a concepção de acolhimento problematizada e ancorada nos saberes necessários à prática docente, apontados por Freire (1996), passa por (re)conhecer o inacabamento, que impulsiona a busca permanente pelo aprender e pela adoção de uma atitude de constante diálogo e crítica em relação à prática pedagógica.

Explica Freire (1996) que: 
É na inconclusão do ser, que se sabe como tal, que se funda a educação como processo permanente. Mulheres e homens se tornaram educáveis na medida em que se reconheceram inacabados. Não foi aeducação que fez mulheres e homens educáveis, mas a consciência de sua inconclusão é que gerou sua educabilidade. É também na inconclusão de que nos tornamos conscientes e que nos inserta no movimento permanente de procura que se alicerça a esperança. "Não sou esperançoso", disse certa vez, por pura teimosia, mas por exigência ontológica. Este é um saber fundante da nossa prática educativa, da formação docente, o da nossa inconclusão assumida. (FREIRE, 1996, p. 64-65).

Tomando como premissa as ideias freirianas, pode-se compreender que a formação docente no trabalho com as pessoas com deficiência, bem como em outras relações pedagógicas, precisa ser amparada em saberes epistemológicos que permitam o desenvolvimento da prática pedagógica com as(os) educandas(os) e não para eles e elas. É também nesse sentido que a formação, assim como o ser em formação, é um processo em constante ato de "estar sendo", de constituir-se na relação com aquele que chega. Esta compreensão ajuda a desconstruir os discursos da "insegurança" e do "não saber" como justificativas para não assumir a responsabilidade junto às crianças que têm seu desenvolvimento implicado por alguma deficiência. Nesse sentido, as palavras de Freire nos ensinam que podemos nos sentir seguros, pois,

[...] não há razão para me envergonhar por desconhecer algo. Testemunhar a abertura aos outros, a disponibilidade curiosa à vida, a seus desafios, são saberes necessários à prática educativa. Viver a abertura respeitosa aos outros e, de quando em vez, de acordo com o momento, tomar a própria prática de abertura ao outro como objeto da reflexão crítica, deveria fazer parte da aventura docente. A razão ética da abertura, seu fundamento político, sua referência pedagógica; a boniteza que há nela como viabilidade do diálogo. (FREIRE, 1996, p. 153).

Sustentadas nas perspectivas de "estar disponível" e viver a "abertura ao outro" de Freire, que se constitui a concepção de acolhimento desejada para oatendimento à criança com deficiência na creche, constituiu-se um círculo de cultura (FREIRE, 2018), no qual fazeres e saberes, valorizados no que trazem de contribuição à nossa formação, foram sendo tecidos quais fios do mais puro algodão em mãos ainda inexperientes, mas desejosas de se constituir como um "ser mais". Um ser que pode, ainda que tateante, anunciar o acolhimento às crianças com deficiência como um inédito-viável na creche.

Com o objetivo de socializar a experiência dessa pesquisa, este artigo apresenta os caminhos construídos na interação entre pesquisadoras, educadoras e crianças em que o círculo de cultura se constituiu em um espaço-tempo educativo de conscientização e (trans )formação docente. Um espaço-tempo de autoconhecimento, (re) conhecimento e (re) construção de nossos perfis enquanto docentes. 
BONSANTO, Flávia Alves; MONTEIRO, Sandrelena da Silva. Círculo de cultura: uma experiência metodológica de conscientização e (trans)formação docente para o acolhimento de crianças com

\section{$1 \mathrm{O}$ círculo de cultura enquanto possibilidade metodológica de pesquisa}

No caminhar da pesquisa, que visava problematizar com educadoras de uma creche municipal, localizada na periferia da cidade de Juiz de Fora/MG, que recebe diariamente crianças advindas de famílias pobres do entorno, suas concepções sobre acolhimento, o círculo de cultura surgiu como uma possibilidade metodológica.

A pesquisa se inicia, como deveria ser, com o adentrar o espaço-tempo da creche. De início, conhecer o espaço físico, a organização do tempo, as profissionais, as crianças. Não foi tão rápido o processo de nos inserir naquele cotidiano, que já possuía a sua cultura e o seu próprio modo de "estar sendo".

A recepção simpática nos deixou confortável, mas o desafio era de nos fazer participantes. No exercício de nos colocar no movimento do cotidiano da creche, a observação participante foi a primeira condução. Devagar, durante várias semanas, ao longo de um semestre letivo, fomos circulando no espaço-tempo creche, desde o início da manhã até o final da tarde. Almoçávamos juntas, participávamos do momento do banho das crianças, trocávamos fraldas, secávamos lágrimas e sorríamos. Risos que anunciavam que já podíamos sentar à roda para brincar, para ouvir histórias. E, ao final de cada dia, as anotações diversas no diário de campo constituíam narrativas das experiências. Um caderno simples, usado para fazer registros com detalhe dos nossos encontros.

Assim, pouco a pouco, foi se constituindo os laços que permitiram que um sentimento de confiabilidade se estabelecesse entre pesquisadoras e educadoras. O grupo de educadoras era formado por 15 mulheres. Mulheres fortes, com formação básica à superior, e abertas ao aprendizado, revelavam gestos de disponibilidade àquele(a) que chega. $\mathrm{O}$ mesmo sentimento que tornou possível o círculo de cultura (FREIRE, 2018).

Para entender e poder contar às profissionais da creche sobre o círculo de cultura, buscamos a explicação dada pelo Professor Ernani Maria Fiori, ao prefaciar "Pedagogia do Oprimido", na edição de 1967:

\footnotetext{
O círculo de cultura - no método Paulo Freire - re-vive a vida em profundidade crítica. A consciência emerge do mundo vivido, objetiva-o, problematiza-o, compreendendo-o como projeto humano. Em diálogo circular, intersubjetivando-se mais e mais, vai assumindo, criticamente, o dinamismo de sua subjetividade criadora. Todos juntos, em círculo, e em colaboração, re-elaboram o mundo [...]. (FREIRE, 2018, p. 24).
}

Entendemos que não se trata apenas de uma disposição física das pessoas no espaço ocupado, mas das relações que se estabelecem. Isso porque assumir um movimento de cooperação, de colaboração, no qual pudéssemos expor nossas opiniões, nossos saberes, criticamente constituídos a partir das reflexões sobre a própria prática, aos poucos, foi configurando um círculo 
de cultura, na perspectiva freiriana. Círculo no qual circulava, não em linhas fechadas, mas em fluxos contínuos que se entrecruzavam, a possibilidade de (re)afirmar a práxis freiriana como elemento de conscientização e (trans)formação docente permanente.

Corroborando para o entendimento acerca do círculo de cultura, Loureiro e Franco (2011) afirmam que:

\begin{abstract}
O círculo de cultura - espaço educativo onde transitam diferentes subjetividades e convivem diferentes saberes - assume a experiência do diálogo de forma coletiva e solidária em todos os momentos do processo, de tal sorte que seu produto - o conhecimento gerado - seja resultante dessas situações. No caso, o diálogo não se reduz a instrumento metodológico, é utilizado como forma de comunicação em que a questão da diferença do lugar de enunciação é superada pela questão da diferença como qualidade, como valor de qualificação, como forma de potencializar os saberes que se entrecruzam naquele espaço de aprendizagens, organizando suas práticas e suportando sua articulação na totalidade social onde o que está em jogo é a apropriação social do conhecimento. (LOUREIRO; FRANCO, 2011, p. 8).
\end{abstract}

O pronunciamento docente é potente disparador de conhecimentos que emergem da prática e vão sendo (re) construídos e (re)significados em espiral ao encontrar, por meio da aproximação dialógica, elementos convergentes e divergentes, numa relação permeada pela criticidade, ética, solidariedade e respeito. A práxis do conhecimento vivido auxilia na (re) elaboração das práticas podendo gerar, no atendimento às crianças com deficiência, ações inclusivas, que (trans)formam as perspectivas de intervenção no trabalho pedagógico em genuíno acolhimento.

Desde o momento em que adentramos o espaço-tempo da creche e nos colocamos no movimento de participar daquele cotidiano, buscando compreender que concepções de acolhimento amparavam as práticas das educadoras na relação com as crianças com deficiência, entendíamos as diversas formas de exclusão como "situações-limite". Estas precisavam ser transformadas em "percebidos-destacados" e apresentadas à formação docente enquanto "atolimite": uma forma de objetivar o acolhimento na prática inclusiva, de problematizá-lo e dialogar sobre ele enquanto projeto de humanização na relação com as diferenças.

Para Freire, "situações-limite" são barreiras encontradas na vida pessoal e social que precisam ser superadas. Frente a elas, pode-se tomar a atitude de percebê-las como um obstáculo intransponível ou como algo que existe e que precisa ser rompido. Na primeira atitude, se entrega à simples adaptação, não raro, à submissão. Na segunda, há um empenho no sentido da superação. Aqui a "situação-limite" é percebida de forma crítica, destacada do que está em seu entorno, podendo, assim, ser vista como um problema. Este, ao ser "percebido" e "destacado", de forma consciente da vida cotidiana, constitui o "percebido-destacado", não podendo e não devendo 
BONSANTO, Flávia Alves; MONTEIRO, Sandrelena da Silva. Círculo de cultura: uma experiência metodológica de conscientização e (trans)formação docente para o acolhimento de crianças com

permanecer como tal. Quanto aos "atos-limite", são ações adotadas no sentido de romper as “situações-limite” (FREIRE, 1992).

Ao escolher o círculo de cultura como possibilidade metodológica da pesquisa, fez-se necessário o entendimento de outros conceitos freirianos que, então, nos dariam condições de caminhar, em companhia das profissionais da creche, na busca por entendimento da prática ali presente. Dentre estes conceitos, tornou-se indispensável o entendimento de: "situações-limite", “tema gerador" e "inédito-viável”. O “inédito-viável” pode ser compreendido como uma questão inédita, ainda não claramente conhecida e vivida, mas sonhada e que, quando destacada pelos que sonham, passa a ser reconhecida como uma possibilidade de realidade (FREIRE, 1992).

Quando pensamos o direito público subjetivo à educação no Brasil, podemos verificar que na Constituição Federal atual a educação é para todos, mas a prática deste direito é algo que ainda precisa ser (re)pensada. Uma das formas contempladas no trabalho de proporcionar às crianças com deficiência um atendimento que seja, verdadeiramente, inclusivo e com respeito às diferenças, foi fomentar junto às educadoras da creche uma reflexão quanto à(s) forma(s) de acolhimento que ali se faziam presentes. Para tal, buscamos sustentação nas ideias de Paulo Freire, especialmente no que se refere à liberdade, ao respeito e à amorosidade.

Ao longo dos encontros diários, no movimento da observação participante, começávamos a fomentar o entendimento de "situação-limite", que ali se objetivava na reflexão quanto à situação de "exclusão" vivida pelas pessoas com deficiência ao longo da história da humanidade. Nosso entendimento, que também era socializado com as profissionais, sobre o conceito de "situaçãolimite" se fez no diálogo com os apontamentos encontrados em Freire (2018):

\footnotetext{
Ao se separarem do mundo, que objetivam, ao separarem sua atividade de si mesmos, ao terem o ponto de decisão de sua atividade em si, em suas relações com o mundo e com os outros, os homens ultrapassam as "situações-limite", que não devem ser tomadas como se fossem barreiras insuperáveis, mais além das quais nada existisse. No momento mesmo em que os homens as apreendem como freios, em que elas se configuram como obstáculos à sua libertação, se transformam em "percebidos destacados" em sua "visão de fundo". Revelam-se, assim, como realmente são: dimensões concretas e históricas de uma dada realidade. (FREIRE, 2018, p. 125).
}

Ao revelar a exclusão como "situação-limite", conseguimos dar o primeiro passo para ultrapassar a(s) limitação(ões) que dela nascem. A exclusão das pessoas com deficiência é percebida e destacada como uma dimensão concreta e histórica da nossa realidade, a partir da qual podem ser elencados temas e problematizadas possibilidades esperançosas de transformação.

Nesse movimento, aos poucos, as ideias de "inclusão" e de "respeito às diferenças" como temas amplamente discutidos e defendidos na atualidade, e que emergem das visões de mundo e 
BONSANTO, Flávia Alves; MONTEIRO, Sandrelena da Silva. Círculo de cultura: uma experiência metodológica de conscientização e (trans)formação docente para o acolhimento de crianças com

dos valores disseminados no contexto social, começam a ser configuradas como "temas geradores" (FREIRE, 2018). Começa a ser criado o campo propício ao círculo de cultura, que então terá a relação "exclusão-inclusão" como tema gerador de fundo:

Uma unidade epocal se caracteriza pelo conjunto de ideias, de concepções, esperanças, dúvidas, valores, desafios, em interação dialética com seus contrários, buscando plenitude. A representação concreta de muitas destas ideias, destes valores, destas concepções e esperanças, como também os obstáculos ao ser mais dos homens, constituem os temas da época. Frente a este "universo" de temas que dialeticamente se contradizem, os homens tomam suas posições também contraditórias, realizando tarefas em favor, uns, da manutenção das estruturas, outros, da mudança. [...] Os temas se encontram, em última análise, de um lado, envolvidos, de outro, envolvendo as "situações-limite", enquanto as tarefas que eles implicam, quando cumpridas, constituem os "atos-limite" [...]. (FREIRE, 2018, p. 128-129).

Nesta perspectiva, Freire (2018) orienta sobre a necessidade de que esses temas sejam percebidos enquanto aqueles que são envolvidos e que envolvem as "situações-limite". Destaca que as respostas dadas aos mesmos, pela humanidade, ao longo da sua história, somente adquirirão um caráter autêntico e crítico na medida em que estes forem destacados e entendidos como resultados de determinantes históricos, os quais podem e precisam ser (trans)formados. Só assim é possível visualizar "mais além delas e em relação com elas, o inédito-viável." (FREIRE, 2018, p. $130)$.

Também, nesse sentido, o acolhimento é pensado como uma prática de respeito e solidariedade, além de ser visto como um projeto de humanização na relação com as diferenças. Como um "inédito-viável" no contexto das práticas educativas na creche em que a "exclusão" e a indiferença deem lugar a "inclusão" como prática de humanização e "comunhão" com as diferenças (MARQUES, 2012).

Fomentar as ideias freirianas de abertura e respeito ao outro revelou a possibilidade esperançosa de transformação social pela via da ação humana, solidária e cidadã com as educadoras da creche por meio do desenvolvimento de um trabalho pedagógico, coerente com um projeto de sociedade inclusivo e mais justo.

Portanto, pode-se dizer que a busca pela compreensão e (trans)formação da concepção de acolhimento das educadoras em relação ao atendimento às crianças com deficiência na creche foi um "ato-limite", no sentido de investigar, na relação com os temas geradores "inclusão" e "respeito às diferenças", a possibilidade do "acolhimento" fomentado como um "inédito-viável". Experimentamos a percepção, de maneira crítica, de que podemos "ser mais", mais humanos, mesmo diante de barreiras que insistem em ser excludentes. Constatamos o limite, mas olhando 
BONSANTO, Flávia Alves; MONTEIRO, Sandrelena da Silva. Círculo de cultura: uma experiência metodológica de conscientização e (trans)formação docente para o acolhimento de crianças com

além dele. Assumimos uma possibilidade de existência na qual a exclusão seja freada, negada, investigada, problematizada e transformada.

\section{O círculo de cultura enquanto espaço-tempo de (trans)formação docente}

Para Freire (2018, p. 136), “investigar o tema gerador é investigar, repitamos, o pensar dos homens referido à realidade, é investigar seu atuar sobre a realidade, que é sua práxis”. Foi com esse entendimento que visualizamos o círculo de cultura enquanto um espaço-tempo propício à (trans)formação docente na creche.

Tudo aquilo que nos circunda, aquilo que vivemos, vemos, sentimos, conhecemos, problematizamos, refletimos e promove a conscientização faz parte do nosso desenvolvimento, dá solidez a nossa existência histórica. Existência que, se experimentada com esperança, pode possibilitar a constatação de caminhos justos, de (trans)formação. Para Freire (1996, p. 81), a “esperança é um condimento indispensável à experiência histórica. Sem ela, não haveria História, mas puro determinismo”. Inspirada nessa esperança, a possibilidade de mudança se constitui o exercício de pesquisa.

A partir da entrada no espaço-tempo da creche, narrativas, construídas com elementos surgidos na observação participante, e registradas no diário de campo, foram sendo tecidas, constituindo-se em momentos de reflexão sobre nossa presença naquele cotidiano: o que nos dizia, o que nos sugeria (sentimentos, pensamentos, emoções)... Um emaranhado de fios que eram trançados em uma trama chamada educação. Com essa tessitura, a possibilidade de uma práxis (trans)formadora. Sobre a práxis, Romão e Gadotti (2012) nos explicam que:

\footnotetext{
No campo político, portanto, ontologicamente - naquele sentido social que lhe conferiu Lukács - uma práxis se torna revolucionária quando ela não pode abandonar a imperatividade de criar, coletivamente, transindividualmente, uma nova ordem econômica, política, social e cultural, mas sempre a partir da ordem social instituída, com a qual estabelece uma relação dialética (de superação), em que as "situações-limites" se tornam "inéditos-viáveis". (ROMÃO; GADOTTI, 2012, p. 22).
}

E foi com esse pensamento que, ao final de algumas semanas, propusemos às profissionais da creche um espaço-tempo para que pudéssemos conversar sobre o que vínhamos vivendo até ali: nascia o convite para a configuração e, talvez, a objetivação do círculo de cultura. Entendemos que esse não seria apenas um momento, alguns minutos, que sentaríamos juntas em círculo para um diálogo. Mas, sim, um processo nada simples, que foi sendo construído a partir de uma aproximação diária, em que as profissionais se abriram a nossa chegada, e nós nos colocamos no 
BONSANTO, Flávia Alves; MONTEIRO, Sandrelena da Silva. Círculo de cultura: uma experiência metodológica de conscientização e (trans)formação docente para o acolhimento de crianças com

lugar de quem chega não para fazer um diagnóstico, ou julgamentos, mas de quem chega e pede para aprender o que está sendo feito.

Sem ignorar que nossa presença poderia contribuir, nos colocávamos na condição de socializar as teorias que vínhamos estudando e de compartilhar como nos ajudavam a olhar aquele universo. No entanto, aceitar fazer parte não era uma imposição. Assim como nós poderíamos estar ali sem que nada nos afetasse no sentido de nos (trans)formar, também, cada uma daquelas profissionais poderia estar ali sem que nenhum acontecimento fosse capaz de (trans)formá-la. Mas, apostando na esperança e no desejo do aprender, pesquisadoras e educadoras se fizeram protagonistas da mesma investigação.

Este apontamento é muito importante porque, para além da compreensão acerca da concepção de acolhimento que permeia as práticas com as crianças com deficiência na creche, fomentou-se a humanização no acolhimento, o respeito e a valorização das diferenças e da amorosidade na prática educativa. Freire (2018) nos lembra que:

É preciso que nos convençamos de que as aspirações, os motivos, as finalidades que se
encontram implicitados na temática significativa são aspirações, finalidades, motivos
humanos. Por isto, não estão aí, num certo espaço, como coisas petrificadas, mas estão
sendo. São tão históricos quanto os homens. Não podem ser captados fora deles,
insistamos. Captá-los e entendê-los é entender os homens que os encarnam e a realidade
e eles referida. Mas, precisamente porque não é possível entendê-los fora dos homens, é
preciso que estes também os entendam. A investigação temática se faz, assim, um esforço
comum de consciência da realidade e de autoconsciência, que a inscreve como ponto de
partida do processo educativo, ou da ação cultural de caráter libertador. (FREIRE, 2018,
p. 138).

A reflexão da prática, em prol da tomada de consciência em relação à inclusão das crianças com deficiência e da conscientização com vistas à adoção de uma práxis respeitosa e acolhedora, é um sonho viável no contexto de (trans)formação cotidiana das educadoras da creche.

O fato de entender a investigação temática como parte de um contexto histórico e cultural implica que tenhamos que considerar não apenas os sujeitos que participam da discussão, mas também o contexto no qual esta se dá. Nesse caso específico, trata-se de uma creche pública em um município do interior de Minas Gerais. Na dinâmica da cidade, essa creche está localizada no seio de um bairro de periferia, que atende a uma comunidade que vive em situação de vulnerabilidade social, com pouco acesso aos direitos que lhes são garantidos pela Constituição Federal Brasileira. As participantes da pesquisa eram todas mulheres: pesquisadoras e profissionais da creche. Mulheres que vivem quotidianamente com as crianças, conhecedoras de suas realidades familiares e sociais, e que não se deixam vencer pelas situações-limite que as condições de trabalho 
BONSANTO, Flávia Alves; MONTEIRO, Sandrelena da Silva. Círculo de cultura: uma experiência metodológica de conscientização e (trans)formação docente para o acolhimento de crianças com deficiência na creche

lhes impõem. Dia após dia, recriam possibilidades outras de se fazer educadoras de crianças pequenas.

Além dos encontros diários, foi combinado um dia e horário específicos, em que apenas nós, mulheres adultas, ocupamos o espaço-tempo da creche para (trans)formação. Em roda, as quinze profissionais da creche e as duas pesquisadoras, convidadas ao diálogo suscitado pelo tema gerador "inclusão" e "respeito às diferenças", viram a possibilidade de provocar a (re)tomada de consciência em relação ao acolhimento que era oferecido às crianças com deficiência que chegavam e, quiçá, ao revisitar o já feito, fazer adoção de outras e conscientes práticas pedagógicas, amparadas pelas ideias freirianas.

Sobre a Conscientização e a Tomada de Consciência, Freire (2018) nos sinaliza que:

Daí que seja a conscientização o aprofundamento da tomada de consciência, característica, por sua vez, de toda emersão. Neste sentido é que toda investigação temática de caráter conscientizador se faz pedagógica e toda autêntica educação se faz investigação do pensar. Quanto mais investigo o pensar do povo com ele, tanto mais nos educamos juntos. Quanto mais nos educamos, tanto mais continuamos investigando. Educação e investigação temática, na concepção problematizadora da educação, se tornam momentos de um mesmo processo. (FREIRE, 2018, p. 142).

Foi nesse contexto e, em meio a muitas reflexões, que se constituiu, baseado em princípios freirianos, o círculo de cultura como possibilidade metodológica para a pesquisa.

\section{O círculo de cultura enquanto espaço-tempo de conscientização da/na relação com a criança na creche}

Ao refletir sobre a concepção de acolhimento às crianças com deficiência na creche, acreditamos ser fundamental "estar à disposição" e "ter sensibilidade" em relação às necessidades e aprendizagens que serão apresentadas por elas no decorrer das atividades. Pensar essa relação com o outro implica pensar também a prática pedagógica com ele desenvolvida. Nesta teia, Arroyo (2014) aponta que:

\footnotetext{
$\mathrm{Na}$ medida em que outros educandos chegam com outras experiências sociais, outras culturas, outros valores, mostrando-se Outros Sujeitos nas relações políticas, econômicas, culturais, Outras Pedagogias são inventadas, outras formas de pensá-los e de pensar a educação, o conhecimento, a docência são reinventadas. Os Outros Sujeitos pressionam as concepções pedagógicas a repensar-se nos processos de sua produção teórica, epistemológica. (ARROYO, 2014, p. 11).
}

Reconhecendo a necessidade de problematizar as práticas de acolhimento, de tal forma que a reflexão se fizesse de forma crítica e autônoma, foi proposta às educadoras uma leitura a partir dos elementos, apontados por Freire (1996), como necessários à prática educativa com autonomia. 
BONSANTO, Flávia Alves; MONTEIRO, Sandrelena da Silva. Círculo de cultura: uma experiência metodológica de conscientização e (trans)formação docente para o acolhimento de crianças com

E assim o fizemos, tomando-os do livro "Pedagogia da Autonomia". Após esse momento, analisamos juntas se haviam elementos convergentes e/ou divergentes nas práticas cotidianas.

Fomos surpreendidas positivamente ao constatar que vários dos saberes apontados por Freire (1996) faziam parte da concepção e da prática das educadoras da creche. Alguns descritos explicitamente, outros com sinônimos, significações múltiplas, mas, sobretudo, ações esperançosas. Naquele tecer de concepções e reflexões, havia o respeito aos saberes e autonomia das crianças; a corporificação das palavras pelo exemplo; a aceitação do novo e a rejeição a qualquer forma de discriminação; a reflexão crítica sobre a prática; a consciência do inacabamento; o bom senso; a tolerância; a luta em defesa dos direitos das educadoras; a alegria e a esperança; a convicção de que a mudança é possível; a curiosidade; a segurança; a competência profissional; a generosidade; o comprometimento; a liberdade; a tomada consciente de decisões; o saber escutar; a disponibilidade para o diálogo e o querer bem nas relações interpessoais.

No entanto, mais importante que verificar indícios de tais saberes, foi confirmar a esperança confiante que se estampava no rosto de cada uma daquelas profissionais. O identificar-se com o pensamento de Paulo Freire era como uma aprovação do esforço ali desenvolvido no sentido de construir uma creche inclusiva. De patrono da educação brasileira, Freire, naquele momento, tornava-se um interlocutor possível, que não só entendia as angústias e inacabamentos, mas, especialmente, respeitava o esforço de cada uma "estar sendo" o seu melhor a cada dia.

Fazia-se, quase que palpável, o entendimento de que os vários elementos que constituem a prática pedagógica partem de alguém, de um lugar, de um ponto de vista, de uma concepção de mundo, de ser no mundo, de estar nele e (con)viver com o Outro. O respeito ao Outro e às suas especificidades revelavam a possibilidade freiriana de comunhão, diálogo, transformação, inclusão.

Refletindo sobre a atuação docente, potencialmente acolhedora, Freire (1996) nos permite considerar que:

\footnotetext{
A professora democrática, coerente, competente, que testemunha seu gosto pela vida, sua esperança no mundo melhor, que atesta sua capacidade de luta, seu respeito às diferenças, sabe cada vez mais o valor que tem para a modificação da realidade, a maneira consistente com que vive sua presença no mundo, de que sua experiência na escola é apenas um momento, mas um momento importante que precisa de ser autenticamente vivido. (FREIRE, 1996, p. 127).
}

Animadas e esperançosas, finalizávamos os últimos pontos daquela tessitura. Mas, ainda, havia o lugar para a manifestação da necessidade de outros espaços-tempos como aquele, em que era possível manifestar a indignação pelo desrespeito edesvalorização das ações de cuidar e educar da creche, na educação infantil. Seja pela comparação com as ações pedagógicas de outras etapas da educação básica, seja por qualquer outro motivo. Esse desrespeito é vivido por elas, inclusive, 
no que se refere à remuneração. E, também ali, havia uma orientação cuidadosa de Freire (1996) ao chamar a atenção para o fato de que:

Se há algo que os educandos brasileiros precisam saber, desde a mais tenra idade, é que a luta em favor do respeito aos educadores e à educação inclui que a briga por salários menos imorais é um dever irrecusável e não só um direito deles. A luta dos professores em defesa de seus direitos e de sua dignidade deve ser entendida como um momento importante de sua prática docente, enquanto prática ética. Não é algo que vem de fora da atividade docente, mas algo que dela faz parte. (FREIRE, 1996, p. 74).

Indiscutivelmente, o círculo de cultura como possibilidade metodológica de pesquisa foi um diferencial na construção de conhecimento, na reflexão e (re)significação de concepções e práticas de acolhimento à criança com deficiência na creche. Talvez o mais importante não é a configuração teórica em si, mas entender a pesquisa como um processo de/em construção em que todos os envolvidos são respeitados em seu inacabamento. E este sendo visto como um "inéditoviável", a construção do sonho possível de uma educação mais humanizada desde a creche.

Certamente, um dos principais aprendizados é que, para (re)significar concepções e (trans)formar práticas, é imprescindível o respeito àquilo que cada profissional acredita como necessário à prática pedagógica, enquanto qualidade e virtude humanas. Somente assim será possível defender e reafirmar o acolhimento enquanto uma prática de inclusão, um "inédito-viável" no horizonte não apenas de uma creche, mas no atendimento a toda e a qualquer criança em todo e qualquer espaço-tempo educacional.

\section{Considerações finais}

A riqueza do vivido é imensurável. Ouvimos as concepções de cada uma das educadoras em respeito às suas culturas e leituras de mundo, e (re)significamos juntas a concepção de acolhimento às crianças com deficiência na creche. Partimos, respeitosamente, daquilo que cada uma acredita ser necessário na prática pedagógica, enquanto qualidade e virtude humanas, para (re)significar estas ações como saberes fundamentais à prática educativa inclusiva.

Podemos considerar que o círculo de cultura vivenciado na creche (re)significou a solidariedade como virtude humana essencial à prática do acolhimento das crianças com deficiência. Da mesma forma, (re)significamos que a inclusão é uma ação, esclarecendo o equívoco histórico de que ela seja apenas um conceito, usualmente, aplicado às teorias atuais. E que o “acolhimento” é uma prática de inclusão, um inédito-viável no espaço-tempo educacional. 
BONSANTO, Flávia Alves; MONTEIRO, Sandrelena da Silva. Círculo de cultura: uma experiência metodológica de conscientização e (trans)formação docente para o acolhimento de crianças com deficiência na creche

\section{Referências}

ARROYO, Miguel G. Outros Sujeitos, Outras Pedagogias. 2 ed. Petrópolis, RJ: Vozes, 2014.

FREIRE. Paulo. Pedagogia da autonomia: saberes necessários à prática docente. 3. ed. São Paulo: Paz e Terra, 1996.

FREIRE. Paulo. Pedagogia da esperança: um reencontro com a Pedagogia do Oprimido. Rio de Janeiro: Paz e Terra, 1992.

FREIRE. Paulo. Pedagogia do oprimido. 65. ed. Rio de Janeiro/São Paulo: Paz e Terra, 2018.

LOUREIRO, Carlos Frederico B.; FRANCO, Jussara Botelho. Aspectos teóricos e metodológicos do círculo epistemológico de cultura: uma possibilidade pedagógica e dialógica em educação ambiental. In: Encontro "Pesquisa em Educação Ambiental" - A pesquisa em Educação Ambiental e a Pós-Graduação no Brasil. 4., 2011. Ribeirão Preto. Disponível em:

http://brasil.campusvirtualsp.org/sites/default/files/CirculonaEduAmbient.pdf. Acesso em: 10 Abr. 2019.

MARQUES, Luciana Pacheco. Cotidiano escolar e diferença. In: Educação em Foco, Juiz de Fora, v. 17, n. 1, p. 101-117, mar./jun. 2012. Disponível em: http://www.ufff.br/revistaedufoco/files/2012/10/Cotidiano-escolar-e-. Acesso em: 09 ago. 2016.

ROMÃO, José Estáquio; GADOTTT, Moacir. Paulo Freire e Amílcar Cabral: a descolonização das mentes. São Paulo: Editora e Livraria Instituto Paulo Freire, 2012. 